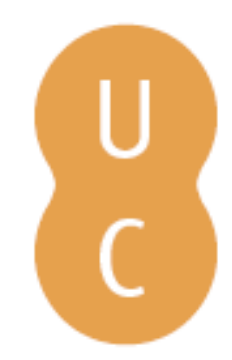

\title{
nommalina
}

\section{Operações de combate a incêndios na interface urbano-florestal}

\author{
Autor(es): $\quad$ Fidalgo, Emanuel
}

Publicado por: Imprensa da Universidade de Coimbra; RISCOS - Associação

URL

persistente: URI:http://hdl.handle.net/10316.2/34927

DOI: $\quad$ DOI:http://dx.doi.org/10.14195/978-989-96253-3-4_127

Accessed : $\quad$ 26-Apr-2023 14:05:43

A navegação consulta e descarregamento dos títulos inseridos nas Bibliotecas Digitais UC Digitalis, UC Pombalina e UC Impactum, pressupõem a aceitação plena e sem reservas dos Termos e Condições de Uso destas Bibliotecas Digitais, disponíveis em https://digitalis.uc.pt/pt-pt/termos.

Conforme exposto nos referidos Termos e Condições de Uso, o descarregamento de títulos de acesso restrito requer uma licença válida de autorização devendo o utilizador aceder ao(s) documento(s) a partir de um endereço de IP da instituição detentora da supramencionada licença.

Ao utilizador é apenas permitido o descarregamento para uso pessoal, pelo que o emprego do(s) título(s) descarregado(s) para outro fim, designadamente comercial, carece de autorização do respetivo autor ou editor da obra.

Na medida em que todas as obras da UC Digitalis se encontram protegidas pelo Código do Direito de Autor e Direitos Conexos e demais legislação aplicável, toda a cópia, parcial ou total, deste documento, nos casos em que é legalmente admitida, deverá conter ou fazer-se acompanhar por este aviso.

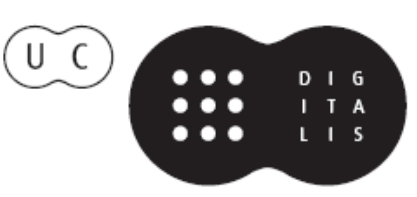



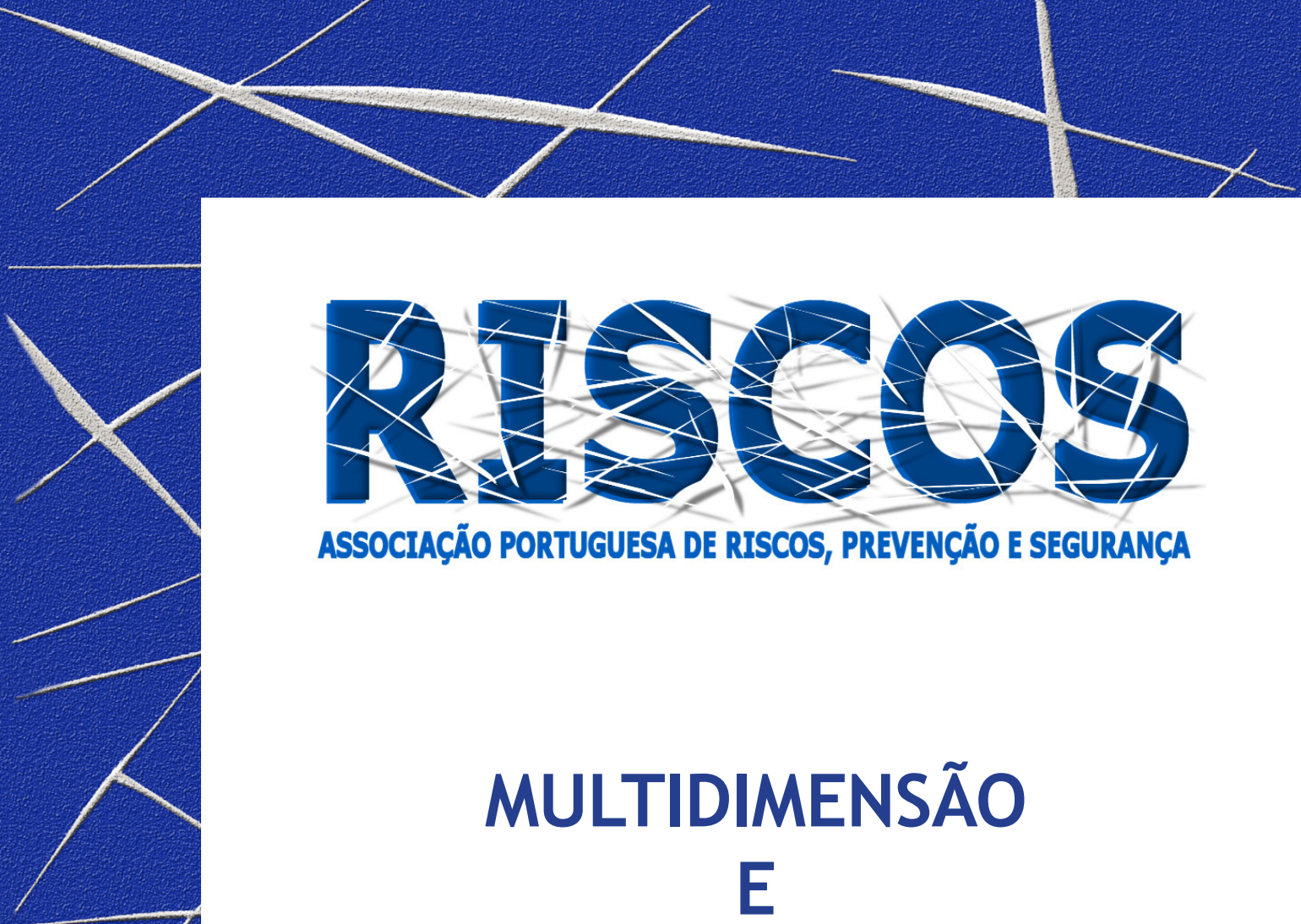

ASSOCIAÇÃO PORTUGUESA DE RISCOS, PREVENCCÃO E SEGURANÇA

MULTIDIMENSÃO

E
TERRITÓRIOS DE RISCO

III Congresso Internacional

I Simpósio Ibero-Americano

VIII Encontro Nacional de Riscos

Guimarães

2014 


\title{
OPERAÇÕES DE COMBATE A INCÊNDIOS NA INTERFACE URBANO-FLORESTAL
}

\author{
Emanuel Fidalgo \\ Corpo de Bombeiros Voluntários de Baião \\ emanuel.s.fidalgo@gmail.com
}

\begin{abstract}
RESUMO
A maior frequência e severidade dos incêndios em áreas de interface urbano -florestal (IUF) em Portugal é um facto. Estas áreas resultam de duas situações distintas, por um lado, aquelas em que se verifica o abandono das atividades agrícola, silvícola e pastoril, verificando-se o aumento dos matos e o seu avanço sobre povoamentos urbanos. Por outro lado, aquelas áreas em que a expansão urbanística leva ao «avanço» das áreas urbanas (habitações, comércio, indústrias, etc.) sobre os subúrbios envolventes.

Ao contrário da atual resposta operacional aos incêndios em áreas de IUF, esta não tem necessariamente que ser idêntica a um incêndio florestal, nem se pode confundir um incêndio na IUF como um incêndio urbano a decorrer em simultâneo com um incêndio florestal. Deste modo, é apresentada em forma de reflexão mas também de proposta a abordagem a realizar pelos Bombeiros feita a partir do contributo de diversos Corpos de Bombeiros de Portugal Continental. A mesma abordagem foi elaborada para a caracterização da matriz humana inscrita pelas populações que vivem e percorrem estes territórios, apresentada pelo contributo pelos serviços municipais de proteção civil e dos gabinetes técnicos florestais.
\end{abstract}

Palavras-chave: Interface Urbano Florestal; Combate; Comunidades; Prevenção.

\section{Introdução}

Se por si só a manifestação de incêndios florestais acarreta risco para as populações, nomeadamente aquelas que vivem em espaços rurais, recentemente, a partir do início do século os incêndios têm cada vez mais aproximado de aglomerados populacionais, alguns deles de destaque nacional.

Esta problemática recente é transversal ao território nacional, ainda que com especificidades locais e que tem associados problemas característicos das áreas que se designam de interface urbano-florestal, que mais adiante se designará de IUF. Os territórios que apresentam estes aspetos, caracterizam-se pela promiscuidade entre solo classificado como urbano e florestal.

\section{Bombeiros (in)formados, Bombeiros eficientes}

A formação ministrada aos Corpos de Bombeiros (CB) relativamente aos incêndios, distingue-os claramente em duas grandes tipologias, os incêndios estruturais (urbanos, industriais, etc.) e os incêndios rurais (povoamento florestal, agrícola, etc.), não havendo referência para incêndios na interface urbano-florestal.

Deste modo, sempre que um incêndio assume características de incêndio na IUF em termos de classificação de ocorrência é-lhe atribuída a classificação «tipo» povoamento florestal, mato, agrícola, etc. e caso alguma infraestrutura fique destruída, é mencionada como consequência do incêndio florestal, ou então é considerada uma nova ocorrência do «tipo» urbano ou industrial.

Portanto, em alguns casos subsistem dúvidas quanto às características dos incêndios na IUF. De forma empírica e resultado da experiência e conhecimento do terreno da área de atuação própria de cada $C B$, na generalidade dos incêndios florestais que se aproximam de aglomerados populacionais, os CB's enviam meios que permitam realizar combate e também proteção de 
infraestruturas. No entanto, em situações de maior exigência dos meios de combate, sobretudo quando ocorrem vários incêndios em simultâneo, tal não se verifica. Deste modo, os meios que se dirigem para a ocorrência e após reconhecimento inicial, ainda que fossem com a missão atribuída para combater o incêndio, por prioridades de atuação, acabam por ficar junto dos aglomerados em proteção, pois são em número insuficiente, deixando o incêndio evoluir livremente, ainda que por vezes, o incêndio não chegue a atingir esse aglomerado populacional ou infraestrutura.

A formação que os CB's recebem neste domínio, incide sobre as tipologias de incêndios estruturais e incêndios florestais. De lembrar que há um «acentuado défice de instrução/ formação e de cultura de segurança nos bombeiros portugueses mormente nos CB's voluntários e municipais (não sapadores)» (AMARO, 2012).

Por vezes, opções erradas ou precipitadas durante as operações em incêndios na IUF resultam da falta de protocolo quanto à tomada de decisão nestes cenários, nomeadamente ao nível do combate, proteção ou evacuação, uma vez que neste domínio são inexistentes.

Quanto às dificuldades sentidas pelos bombeiros no combate a incêndios em áreas de interface urbano-florestal, estas são de diversa ordem. Por um lado, o especto estrutural visível no "desordenamento" do território, que resulta num intrincado padrão entre o edificado e o rural (florestal, agrícola ou inculto) e que condiciona todas as operações dos bombeiros e por outro, a solicitação múltipla e simultânea dos bombeiros. Assim se explica a grande dispersão de meios num incêndio, sobretudo quando se pretende defender infraestruturas. Outros problemas associados são os arruamentos inacabados ou sem saída, com reduzida dimensão e que dificultam as manobras e o cruzamento dos veículos de combate, ou quando são vias mais antigas (por vezes em terra batida), a falta de manutenção, os buracos e a vegetação a cobrir parte da via revestem-se de verdadeiras armadilhas, quer para os meios de socorro, quer para as pessoas que tentem a fuga.

Mas não só o domínio público se reveste de dificuldades para os bombeiros. Por vezes, a incúria e descuido de proprietários permite a acumulação de resíduos de origem urbana (lixo doméstico, relva seca, etc.) e industrial (aparas de madeira, plásticos, etc.) próximo de infraestruturas que podem despoletar situações de maior intensidade do fogo e desse modo, dificultar a sua extinção, ou até promover a sua propagação a edifícios contíguos. Situações como estas acontecem essencialmente pela falta de civismo de alguns cidadãos, o não cumprimento dos dispostos legais, mas também pela ausência de sensibilização para uma «cultura do risco» e até a ausência de medidas punitivas, por vezes necessárias como solução de recurso.

A criação de uma nova tipologia de incêndio «Incêndio na Interface Urbano-Florestal» só por si, não trará qualquer vantagem, apenas uma designação diferente. Contudo, uma vez que os incêndios na IUF implicam uma abordagem diferente do que convencionalmente sucede nos incêndios florestais e também pelo aumento da sua recorrência, do risco acrescido e dos seus impactes cada vez mais avultados, entende-se pertinente a sua criação.

Esta designação tipológica seria uma forma de identificação clara e inequívoca de uma ação rápida e "musculada” (Figura 1), aliada à necessidade de mobilização de meios adicionais numa ação distinta, mas simultânea das operações de combate, proteção e evacuação.

Esta possível abordagem carece de uma capacidade acrescida de coordenação e cooperação com as forças de segurança, principalmente no que concerne a evacuação. Para tal, será fundamental a criação de um protocolo para bombeiros nestes cenários, à semelhança do que sucede nos incêndios florestais, incêndios urbanos ou no salvamento e desencarceramento, 
permitindo que a atuação dos bombeiros seja rápida, segura e padronizada, evitando-se o improviso, nem sempre com bons resultados.

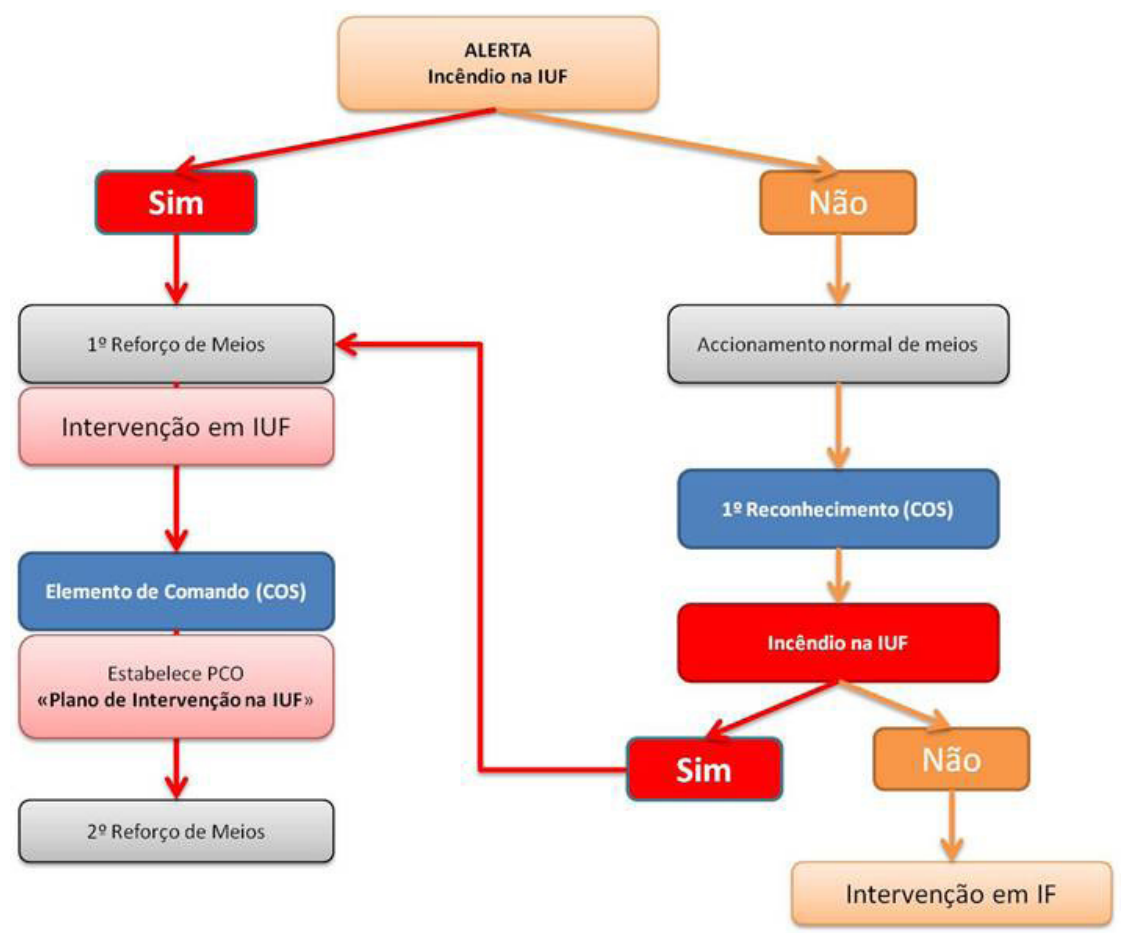

Figura 1 - Representação esquemática das ações a realizar num incêndio na IUF.

\section{Comunidades (in)formadas, Comunidades resilientes}

Apesar das dificuldades dos Municípios fazerem cumprir o DL 124/2006 ratificado pelo DL $17 / 2009$, designadamente no que respeita à realização de faixas de gestão de combustível em torno de habitações e de aglomerados populacionais, e aos encargos financeiros daí resultantes, esta legislação é vista como estruturante na regulação no que concerne à proteção de pessoas e bens em caso de incêndio na interface urbano-florestal. É ainda entendida como fundamental na proteção passiva de edificações, facilitando o combate direto e desse modo garantindo maior proteção das infraestruturas, bem como uma redução significativa no tempo de extinção dos incêndios.

É por vezes subestimado a capacidade das populações realizarem a defesa das suas residências. Uma vez identificadas as populações mais expostas, poderiam realizar-se ações de formação sobre comportamento do fogo e seu combate. Deste modo, ao depararem-se com um incêndio essa comunidade saberia proteger-se, o que permitiria aos bombeiros manterem as suas posições de combate, evitando sobrecarrega-los e desmobiliza-los para realizarem a proteção. Os habitantes das áreas de IUF podem classificar-se relativamente ao período de permanência nas áreas de IUF, em quatro tipos: os moradores permanentes ativos (agricultura e floresta); os moradores permanentes ativos (sector secundário e terciário), ausentes no horário laboral; os moradores permanentes não ativos; e os moradores não permanentes (fins-de-semana e férias). 
Estas quatro tipologias de moradores, com experiências e vivências diferentes vão reagir de maneira distinta ao fogo. Quem sempre viveu no espaço rural, ainda que a sua atividade não seja relacionada com a agricultura ou a floresta, está familiarizado com o fogo, até como prática corrente de destruição de sobrantes, e ao deparar-se com um incêndio reage protegendose. Já o grupo de pessoas que apenas ocasionalmente vive neste território, terá maior dificuldade em avaliar o perigo e nem sempre agirá da forma mais correta, à semelhança dos não ativos, muitas vezes idosos e com mobilidade reduzida, ainda que conheçam melhor o comportamento do fogo.

\section{Conclusão}

Não havendo uma cultura do risco, nem tão pouco qualquer tipo de preparação e sensibilização das populações, não será fácil inverter a tendência que se adivinha no agudizar de situações de incêndios em interface urbano-florestal.

Verifica-se assim que as áreas de IUF têm aumentado, principal consequência da expansão das áreas urbanas e do surgimento de novas edificações, muitas delas desintegradas de qualquer plano de urbanização, isoladas em manchas florestais.

Se muitas vezes a manifestação do risco de incêndio florestal na IUF é inevitável, a recuperação das áreas ardidas deverá ser uma prioridade. Com uma política de ordenamento florestal, poderão corrigir-se factores condicionantes dos incêndios como as extensas áreas de monocultura de pinheiro ou eucalipto sem qualquer descontinuidade. Assim, mesmo que não se evite no futuro a sua ocorrência, pelo menos os seus impactes poderão ser minimizados.

\section{Bibliografia}

AMARO, A. (2012). O Socorro em Portugal. Lisboa: Instituto de Direito Público.

CASTRO, C. et al (2006). Combate a Incêndios Florestais. $3^{a}$ Edição. ENB: Sintra.

LOURENÇO, L. (2006). "Incêndios florestais: algumas reflexões e mitos do combate" in Territorium 13, pp. 59-70. Coimbra.

LOURENÇO, L. et al (2006). Manual de Combate a Incêndios Florestais por equipas de Primeira Intervenção.

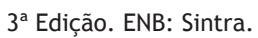

MENDES, J.M.; TAVARES, A.T. (2009). "Building resilience to natural hazards. Practices and policies on governance and mitigation in the central region of Portugal" in Safety, Reliability and Risk Analysis: Vol. 2, Theory, Methods and Applications.pp. 1577-1584. Leiden: CRC Press/Balkema. 